\title{
CFD ANALYSIS OF HYDRODYNAMIC STUDIES OF A BUBBLING FLUIDIZED BED
}

\author{
B.J.M.RAO ${ }^{1}$, K.V.N.S.RAO ${ }^{2}$ \& G. RANGA JANARDHANA ${ }^{3}$ \\ ${ }^{1}$ Department of Mechanical. Engineering., VFSTR University \& Department of .Mechanical \\ Engineering, JNTU Kakinada, Andhra Pradesh, India \\ ${ }^{2}$ Department of Mechanical, Engineering, B. V. R. I. T, Hyderabad, Telangana, India \\ ${ }^{3}$ Department of Mechanical Engineering, JNTUA, Anantapur, Andhra Pradesh, India
}

\begin{abstract}
Fluidization velocity is one of the significant parameter to characterize the hydrodynamic studies of fluidized bed as it determines different flow regimes. Computational Fluid Dynamics simulations are carried for a cylindrical bubbling fluidized bed with a static bed height of $1 \mathrm{~m}$ with $0.150 \mathrm{~m}$ diameter of gasification chamber. The parameter investigated is fluidization velocity in range of $0.05 \mathrm{~m} / \mathrm{s}$ to $0.7 \mathrm{~m} / \mathrm{s}$. Sand with density $2600 \mathrm{~kg} / \mathrm{m}^{3}$ and with a constant particle diameter of sand $385 \mu \mathrm{m}$ is employed for all the simulations. Simulations are conducted utilizing with the commercial Computational Fluid Dynamics software, ANSYS-FLUENT. The bubbling flow regime is appeared above the air inlet velocity of $0.2 \mathrm{~m} / \mathrm{s}$. Bubbling character is increased with increase in inlet air velocities indicated by asymmetrical fluctuations of volume fractions in radial directions at different bed heights

KEYWORDS: Computational Fluid Dynamics (CFD), Bubbling Character, Air Velocity \& Volume Fraction
\end{abstract}

Received: Sep 12, 2017; Accepted: Nov 02, 2017; Published: Nov 16, 2017; Paper Id.: IJMPERDDEC201738

\section{NOTATION}

$\varepsilon_{s} \quad$ Volume fraction of particle/solid

$\varepsilon_{g} \quad$ Volume fraction of air

$\rho_{s} \quad$ Density of particle

$\rho_{g} \quad$ Density of air

$\vec{V}_{s} \quad$ Velocity of solid (vector)

$\bar{t}_{s} \quad$ Stress tensor for solid

$\bar{t}_{g} \quad$ Stress tensor for gas

$\lambda_{g} \quad$ Bulk viscosity of gas

$p_{s} \quad$ Solid pressure $d_{s}$ Diameter of particle

$\varepsilon_{s}^{\max } \quad$ Maximum volume fraction of particle

$\mu_{m}^{\max } \quad$ Maximum viscosity of particle

$C_{D} \quad$ Standard drag coefficient

$\operatorname{Re}_{s} \quad$ Particle Reynolds number

$U_{m f} \quad$ minimum fluidization velocity

$u_{s}^{a d v} \quad$ Advection velocity of solid

$u_{g}^{a d v} \quad$ Advection velocity of gas

$l_{g s} \quad$ Drag force 


$\begin{array}{llll}p_{f} & \text { Frictional pressure } & \mu_{s} & \text { Solid phase viscosity } \\ p_{k} & \text { Kinetic pressure } & \mu_{f} & \text { Frictional viscosity } \\ p_{c} \quad \text { Collisional pressure } & \mu_{k} & \text { Kinetic viscosity } \\ \beta_{g s} \quad \text { Drag coefficient } & \mu_{c} & \text { Collisional viscosity } \\ g_{0} \quad \text { Radial distribution function } & & \\ e & \text { Coefficient of restitution } & & \end{array}$

\section{INTRODUCTION}

Bubbling fluidized bed is broadly utilized as a part of industrial application due of good blending, warmth and mass exchange. Biomass gasification reactor is one for combined heat and power (CHP) production. Flow behavior and fluidization properties in the gasifier were studied, by considering the operating parameters such as pressure drop, minimum fluidization velocity and bubble behavior. These parameters significantly affect the gasifier efficiency and how the hydrodynamic behavior of fluidized bed chamber. Fluidized is critical for deciding on the fine jogging parameters, for appropriate fluidization regime [1-4]

(CFD) was employed to steady the complex phenomena of hydrodynamic actions of gas and solid particles. Two models the Eulerian-Lagrangian and Eulerian-Eulerian are accessible in CFD, for the displaying of multiphase frameworks. Kinetic theory of granular flow (KTGF) is continuum based completely. This model is greater appropriate for simulating big and complicated commercial fluidized mattress. Fluidized bed chambers containing, billions of solid particles. In precept, discrete particle models (DPM) is deliver such facts [5-7]. For exceedingly small gas feed the chamber may additionally contain a dense bed of fluidized solid particles. The matters can be homogeneously fluidized or gas may pass via the bed in the shape of huge bubbles. Further increasing in gas flow rate decreases the bed density and the gasoline - solid containing sample may alternate from dense mattress to turbulent mattress then to fast-fluidized mode and in the end to pneumatic conveying mode. Those fashions however require cords about strong phase rheology and particle particle interaction legal guidelines. In most of these float regimes the relative importance of fuel - particle, particleparticle, and wall interaction is exclusive, it means therefore important to become aware of those regimes to select the appropriate mathematical model [5-8]. The vital trouble in modeling of fluidized mattress gasification (FBG) is the momentum of levels, that is brief and a massive wide form of independent variables, which include particle density size and shape may have an effect on hydrodynamic conduct $[2,3,5]$

Taghipour et al. [7], have conveyed exploratory and computational examinations of gas- solid fluidized bed chamber hydrodynamics. Their model anticipated bed development and gas-solid steam designs were sensibly well and concurring with their experimental results. Huilin et al. [9], has broken down the bubbling fluidized bed with parallel blends, applying multi fluid Eularian CFD model, as per the motor hypothesis of granular stream. They found that, the hydrodynamics of gas bubbling fluidized bed are related with the distribution of particle sizes and the amount of dissipated energy, in particle-particle interactions. Gobin et al.[10], conducted numerical simulation of a fluidized bed, using twophase flow method. They performed time subordinate reproductions, for modern and pilot chamber working conditions. 
Their forecasts were in great subjective concurrence with the watched conduct as for as bed structure weight drop and mean stream administrations. Van Wachem et al.[11], checked tentatively Eulerian-Eulerian gas-strong model reproductions of foaming fluidized beds with existing connections for bubble size or bubble speed utilizing CFX, CFD code. The CFD model is based on a two fluid model including the kinetic theory of granular flow. Zhonget. al [12] investigated the maximum spoutable bed heights of a spout-fluid bed, filled with six forms of Geldart group D particles. The parameters investigated by them are particle size, spout nozzle size and fluidizing gas. They found that, the most extreme spoutable bed structure of spout-liquid bed dimensions, with increasing particle size and gas spout size. Lettieri et al. [13] simulated the changeover of bubbling to slugging regime for a typical Group B material at four fluidizing velocities. The simulations are carried with the Eulerian-Eulerian granular kinetic version available inside the CFX-four code. They presented the consequences, in terms of voidage profiles and bubble size, and estimated transition velocity. Bahareh Estejab et al. [15], conducted the numerical simulations to predict the hydrodynamic behavior of gas solid mixture. They tested different drag models. They found the Huilin-Gidaspow drag model is suitable for single solid phase. Embarek Belhadj et al. [16], carried out numerical simulations and experimental validation of hydrodynamics, in bubbling fluidized bed combustion. The simulation methodology, adopted by them is Eulerian-Eulerian approach, with KTGF theory for solid particles. They validated the results with experimental data and fined to be matched.

In the present exploration paper, hydrodynamics of two-dimensional non-responsive gas-solid fluidizing bedchamber are concentrated computationally. A multi liquid Eulerian model consolidating the kinetic theory for solid is applied, in order to simulate the gas-solid stream at various fluidized speeds.

\section{COMPUTATIONAL METHODOLOGY}

ANSYS FLUENT is utilized for simulation wherein $2^{\text {nd }}$ segregated first order implicit unsteady solver is utilized for multiphase calculations. The usage of Eulerian-Eulerian multi phase version, fashionable k- $\varepsilon$ dispersed Eulerian multi phase model with standard wall functions is used. Gas is taken as continuous phase while sand particles are taken as dispersed phase. Kinetic theory of granular flow has been applied to sand particles. Gidaspow model of inter phase interaction (Solid-Gas) is used. The bed material considered for the analysis is sand, an inert material. Bed fluidizing medium is air.

The continuity equation for each phase is separately as shown:

$$
\begin{aligned}
& \frac{\partial}{\partial t}\left(\varepsilon_{g} \rho_{g}\right)+\nabla \cdot\left(\varepsilon_{g} \rho_{g} \vec{V}_{g}\right)=0 \\
& \frac{\partial}{\partial t}\left(\varepsilon_{s} \rho_{s}\right)+\nabla \cdot\left(\varepsilon_{s} \rho_{s} \vec{V}_{s}\right)=0
\end{aligned}
$$

The only constraint being that total volume fraction has to add up to one.

$$
\varepsilon_{g}+\varepsilon_{s}=1
$$

In the present work, there is no mass transfer among the phases and thus the terms on the right hand side of the equations 1 and 2 are zero.

The gas phase momentum equation can be expressed as: 


$$
\frac{\partial}{\partial t}\left(\varepsilon_{g} \rho_{g} \overrightarrow{V_{g}}\right)+\nabla \cdot\left(\varepsilon_{g} \rho_{g} \overrightarrow{V_{g}} \overrightarrow{V_{g}}\right)=\nabla \cdot \bar{\tau}_{g}-\varepsilon_{g} \nabla P+\varepsilon_{g} \rho_{g} g+\beta_{g s}\left(\overrightarrow{V_{s}}-\overrightarrow{V_{g}}\right)
$$

Where $\mathrm{P}$ is the pressure, $\mathrm{g}$ is the acceleration due to gravity and $\beta s g$ is the drag coefficient the stress tensor $\bar{\tau}_{g}$ is calculated by the following equation:

$$
\bar{\tau}_{g}=\varepsilon_{g} \mu_{g}\left(\nabla \overrightarrow{V_{g}}+\left(\nabla \overrightarrow{V_{g}}\right)^{T}\right)+\varepsilon_{s}\left(\lambda_{g}+\frac{2}{3} \mu_{g}\right) \nabla \cdot \overrightarrow{V_{g}} \bar{I}
$$

Assuming no virtual mass and lift force the solid phase momentum equation can be expressed as:

$$
\frac{\partial}{\partial t}\left(\varepsilon_{s} \rho_{s} \overrightarrow{V_{s}}\right)+\nabla \cdot\left(\varepsilon_{s} \rho_{s} \overrightarrow{V_{s}} \overrightarrow{V_{s}}\right)=\nabla \cdot \overrightarrow{\tau_{s}}-\nabla P_{s}+\varepsilon_{s} \rho_{s} g+\beta_{g s}\left(\overrightarrow{V_{s}}-\overrightarrow{V_{g}}\right)
$$

Where $P_{s}$ is the solid pressure obtained from the Kinetic theory of granular flow? This pressure has three components kinetic, collision and frictional.

\section{SOLVER AND DISCRETIZATION SCHEME}

The section coupled simple technique is performed for pressure-velocity coupling. The second one-order upwind scheme is hired for discretization of momentum, turbulence kinetic strength and turbulence dissipation process and the primary-order upwind scheme is executed for discretization of quantity-fraction equations. The time step of size is $0.001 \mathrm{~s}$ is taken for the solution to converge.

\section{GEOMETRY AND MESH}

The geometry parameters of bubbling fluidized bed reactor are primarily based at the studies work of Chinmayee Patra [14]. Fig.1 (a), shows the geometry of the reactor with its dimensions. The bubbling bed reactor has inner diameters of $0.15 \mathrm{~m}$ and height of $1 \mathrm{~m}$. The unfastened board region has internal diameters of $0.3 \mathrm{~m}$, which shows hydrodynamic study and height of $0.8 \mathrm{~m}$. The geometry is created by the use of industrial software ICEM CFD. After geometry technology, a uniform established mesh has been created, as shown in Fig. 1(b). In this study, total of 39250 cells and 40086 numbers of nodes are used, for simulating Fluidized Bed Gasifier. A finer mesh is adapted in the region of static bed and the generated mesh, as shown in Fig. (c)

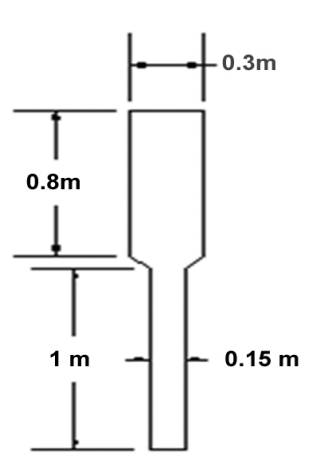

(a) Geometry

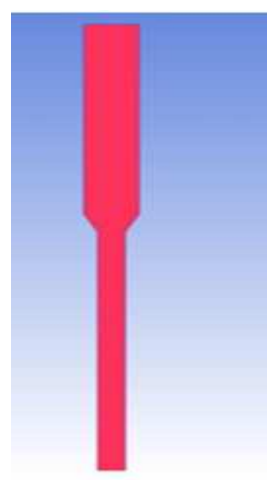

(b) Mesh

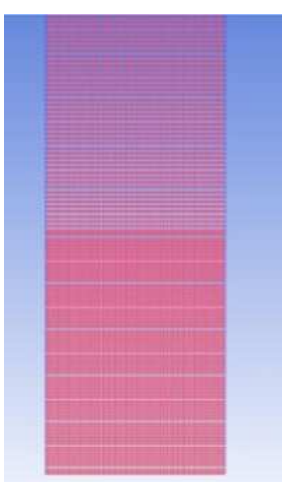

(c) Mesh closure view

Figure 1: Schematic of Geometry and Mesh Generated of Bubbling Fluidized Bed 


\section{RESULTS AND DISCUSSION}

Velocity of fluidizing media, air influence on hydrodynamic behavior of bubbling fluidized bed gasifier has been investigated, using CFD simulations. The simulations are carried with CFD commercial software ANSYS FLUENT. The results in the form of contour plots, vectors and chats have been presented below for solid volume fraction, phase velocity.

Figure. 2 and 3, represents the solid volume fraction contours of sand, for the different air velocities i.e. at $0.05 \mathrm{~m} / \mathrm{s}$, $0.2 \mathrm{~m} / \mathrm{s}, 0.5 \mathrm{~m} / \mathrm{s}$ and $0.7 \mathrm{~m} / \mathrm{s} \mathrm{complete} \mathrm{and} \mathrm{closure} \mathrm{view} \mathrm{at} \mathrm{bed} \mathrm{zone.} \mathrm{At} \mathrm{the} \mathrm{velocity} \mathrm{of} 0.05 \mathrm{~m} / \mathrm{s}$, the bed begins to expand on a small scale, but almost the height of the bed is equal to static bed height. For the air velocity of $0.2 \mathrm{~m} / \mathrm{s}$, bubbles are appeared like surface only and they found in the static bed height, without any appreciable bed growth. The reason attributed may be sand debris, within the bottom part of the bed are in pneumatic transport, while fluidization within the upper portion is in freely bubbling state. At the air velocity of $0.5 \mathrm{~m} / \mathrm{s}$ and $0.7 \mathrm{~m} / \mathrm{s}$, it is observed from contour, the bubbles flow regime is appeared. This might be reason of the segregate tendencies of the particles, towards the partitions or gulf streaming. For that reason, the solid particles slide down along the wall of the reactor, without too much opposition from the upward gas flow.

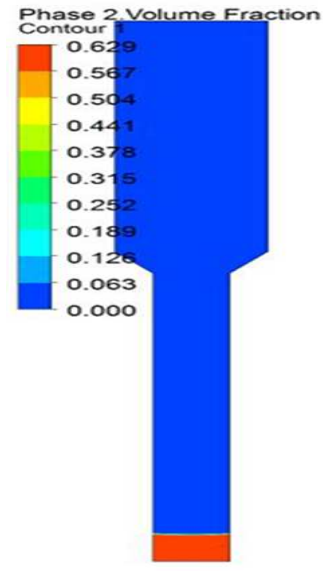

(a) $0.05 \mathrm{~m} / \mathrm{s}$

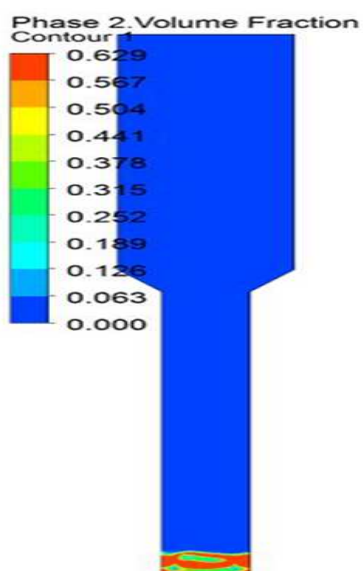

(b) $0.2 \mathrm{~m} / \mathrm{s}$

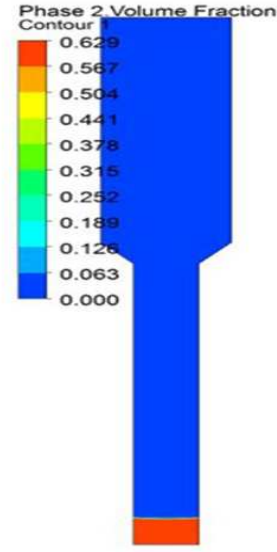

(c) $0.5 \mathrm{~m} / \mathrm{s}$

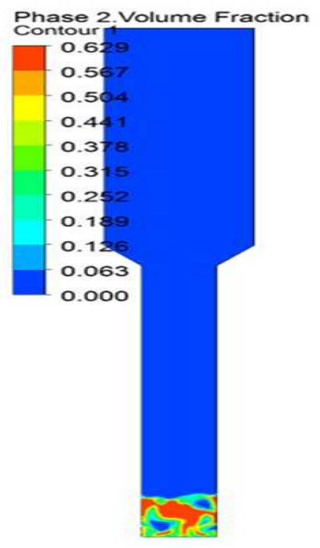

(d) $0.7 \mathrm{~m} / \mathrm{s}$

Figure 2: Sand Volume Fraction Contour at Different Air Velocities for Initial Static Bed Height of $0.1 \mathrm{~m}$ Complete Chamber

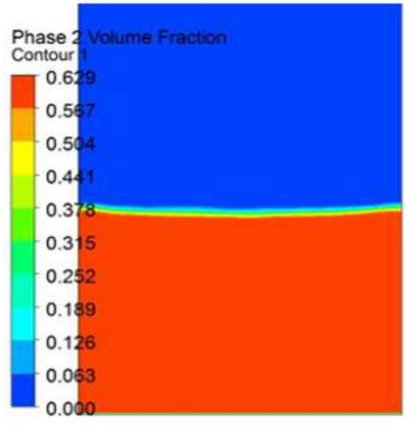

(a) $0.05 \mathrm{~m} / \mathrm{s}$

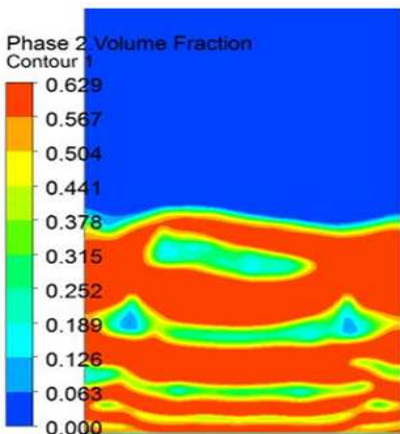

(b) $0.2 \mathrm{~m} / \mathrm{s}$ 


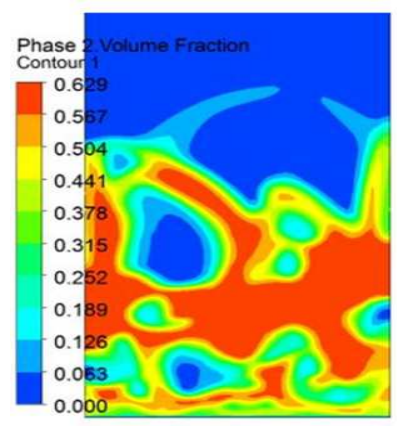

(c) $0.5 \mathrm{~m} / \mathrm{s}$

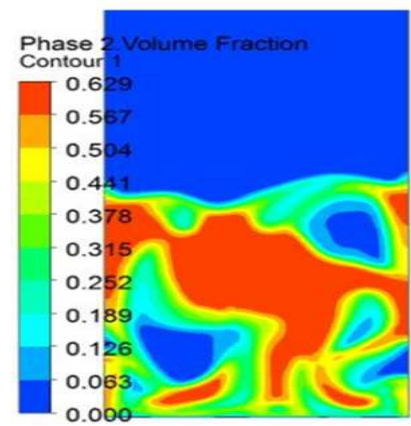

(d) $0.7 \mathrm{~m} / \mathrm{s}$

Figure 3: Sand Volume Fraction Contour at Different air Velocities for Initial Static Bed Height of 0.1m near the Bed Zone

Flow pattern in fluidized bed is shown in form of the velocity vectors for sand in the Fig.4, for different air velocities. It is noticed that, at lower velocities the solid phase velocity is more at the upper surface and lower at the bottom i.e., at $0.05 \mathrm{~m} / \mathrm{s}$ as the velocity increased to $0.2 \mathrm{~m} / \mathrm{s}$, sand is appeared to be lifting in form of surfaces. The bubbling regime is come in to sight at the velocity of $0.5 \mathrm{~m} / \mathrm{s}$. At the velocity $0.7 \mathrm{~m} / \mathrm{s}$, it is noticed that there is aggressive movement of solid particles throughout the bed implying that the velocity at the bottom is less.

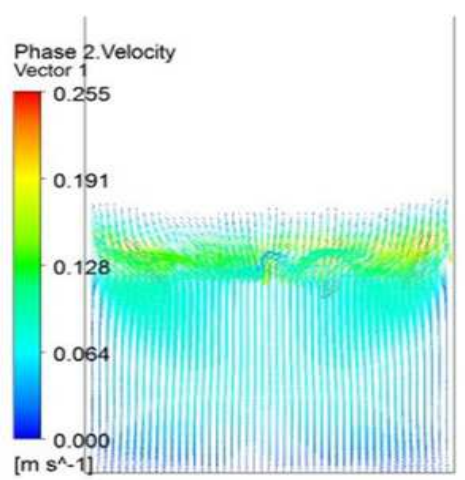

(a) $0.05 \mathrm{~m} / \mathrm{s}$

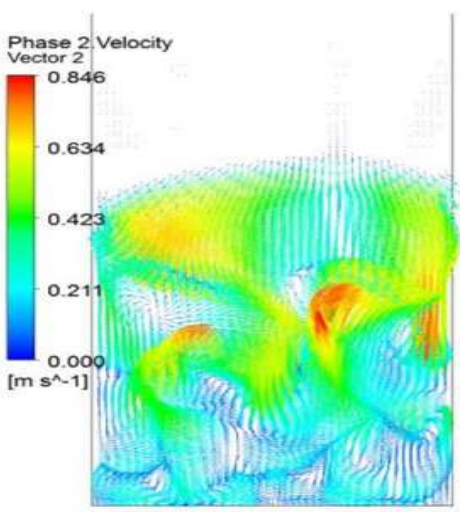

(c) $0.5 \mathrm{~m} / \mathrm{s}$

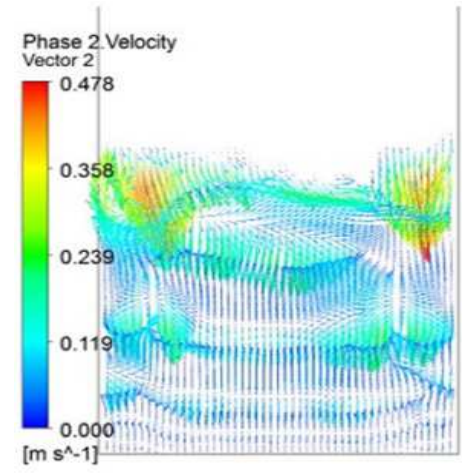

(b) $0.2 \mathrm{~m} / \mathrm{s}$

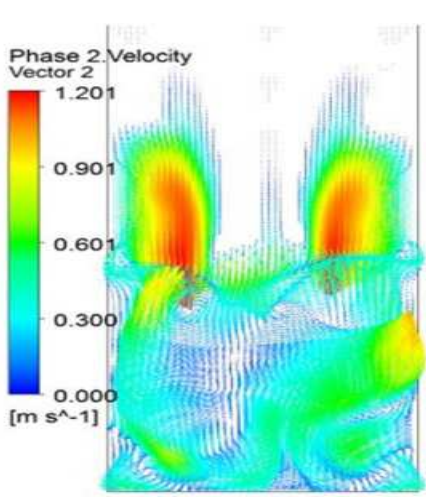

(d) $0.7 \mathrm{~m} / \mathrm{s}$

Figure 4: Velocity Vector of Sand at Different Air Velocities

Figure.5 and 6 represents the complete and closure views of gas phase velocity vectors in the chamber. The gas 
phase's velocity vectors in the chamber are heading upwards and velocity is found to be less at the regions of higher solid volume fraction as the obstruction is more. For the low velocity $0.05 \mathrm{~m} / \mathrm{s}$, the air is not able to penetrate properly through the sand bed. At the velocity $0.2 \mathrm{~m} / \mathrm{s}$, it becomes more and increases further with increase in air velocity.

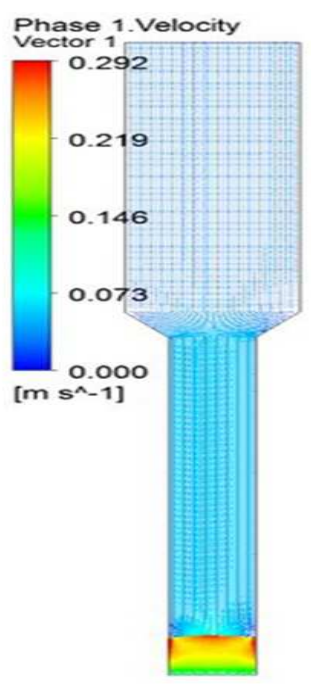

(a) $0.05 \mathrm{~m} / \mathrm{s}$

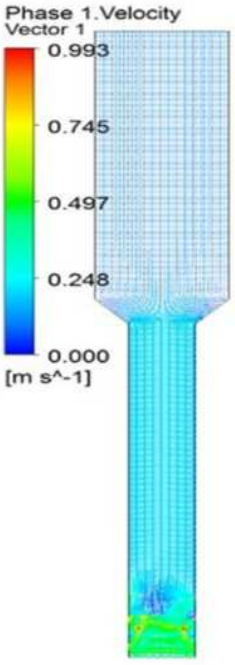

(b) $0.2 \mathrm{~m} / \mathrm{s}$

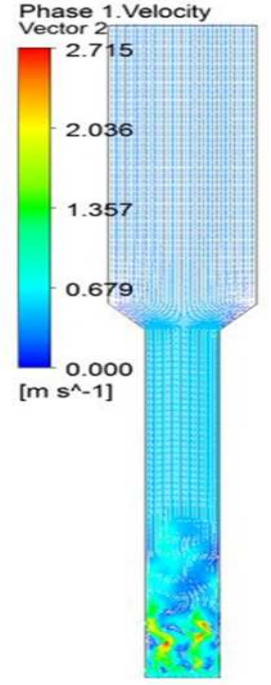

(c) $0.5 \mathrm{~m} / \mathrm{s}$

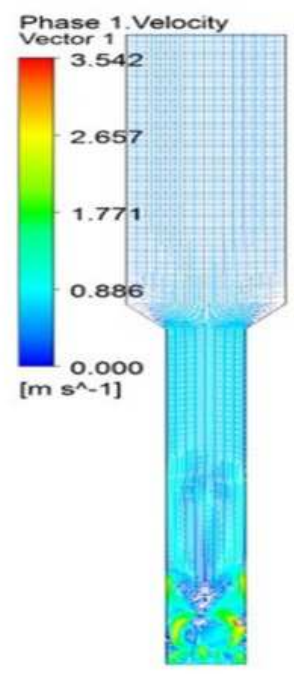

(d) $0.7 \mathrm{~m} / \mathrm{s}$

Figure 5: Velocity Vector of Air at Different Air Velocities in Complete Chamber

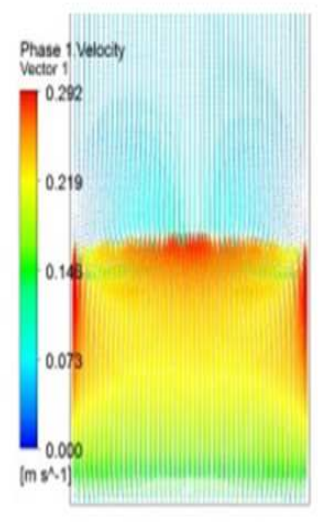

(a) $0.05 \mathrm{~m} / \mathrm{s}$

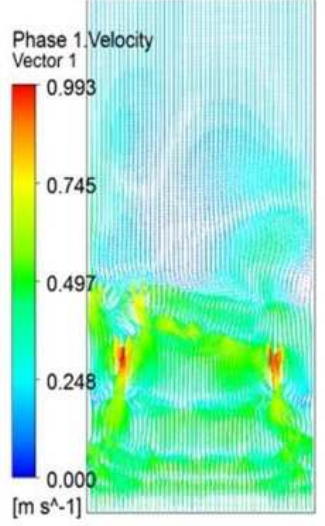

(b) $0.2 \mathrm{~m} / \mathrm{s}$

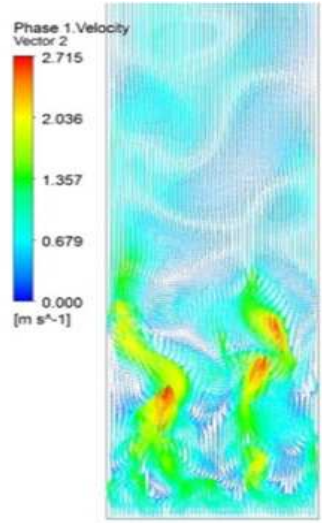

(c) $0.5 \mathrm{~m} / \mathrm{s}$

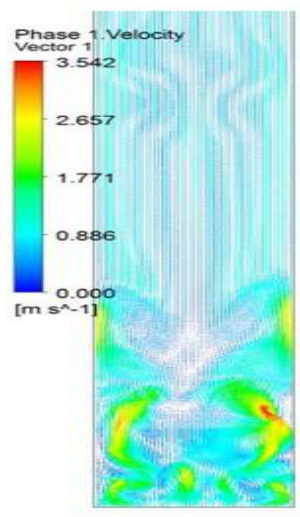

(d) $0.7 \mathrm{~m} / \mathrm{s}$

Figure 6: Velocity Vector of Air at Different air Velocities in Complete Chamber at Closure View

Phase 2 i.e. sand volume fractions are plotted against radial length at dissimilar axial heights as shown in Figure.7. At air velocity $0.05 \mathrm{~m} / \mathrm{s}$ the bed expansion is at small scale only two heights are considered $0.05 \mathrm{~m}$ and $0.1 \mathrm{~m}$. The volume fraction at $0.05 \mathrm{~m}$ is higher and almost constant in radial direction indicating that low air penetration. In addition small scale expansion is indicated at $0.1 \mathrm{~m}$ bed height with slight fluctuation in sand radial distribution. As the velocity is improved to $0.2 \mathrm{~m} / \mathrm{s}$ sand volume fraction at the central core region is less as compared to the wall which indicating the air penetration, which indicates higher particle volume fractions along the walls as compared to the core region. With further increase in velocities to $0.5 \mathrm{~m} / \mathrm{s}$ and $0.7 \mathrm{~m} / \mathrm{s}$ the bubbling regime appeared as it is indicated by asymmetrical fluctuations of volume fractions in radial directions at different bed heights. From the simulation result as shown in the Figure.2. The hydrodynamic model is able to describe quantitatively the accumulation of solids near the wall. 


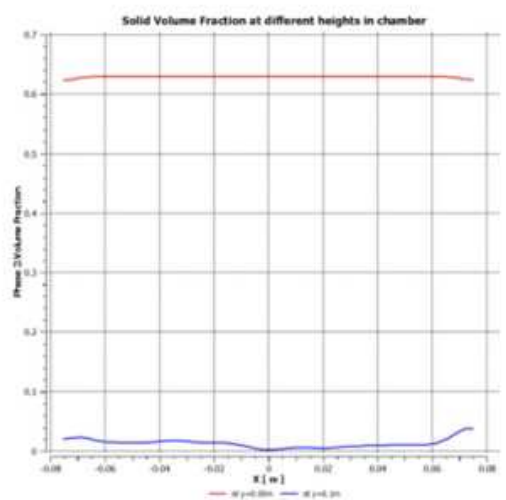

(a) $0.05 \mathrm{~m} / \mathrm{s}$

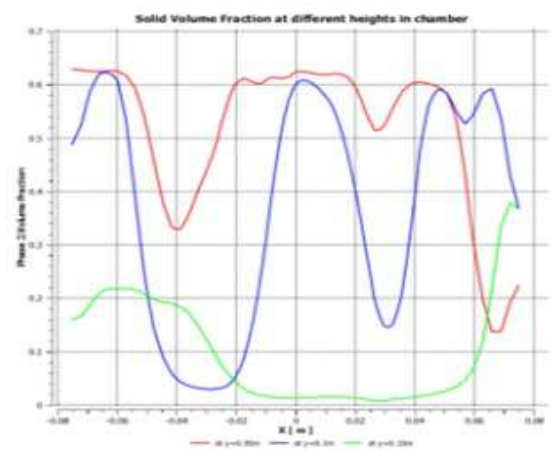

(c) $0.5 \mathrm{~m} / \mathrm{s}$

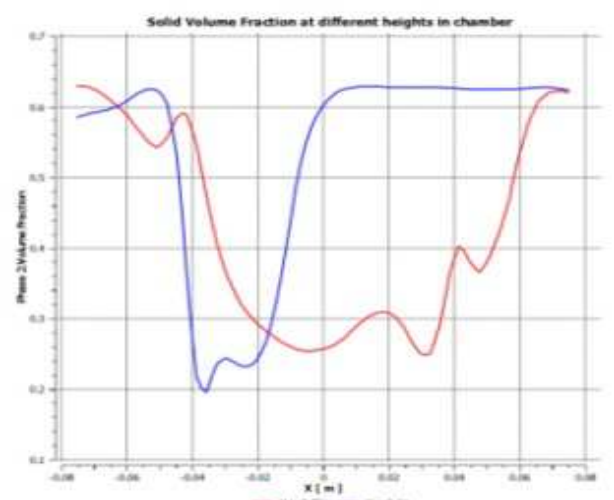

(b) $0.2 \mathrm{~m} / \mathrm{s}$

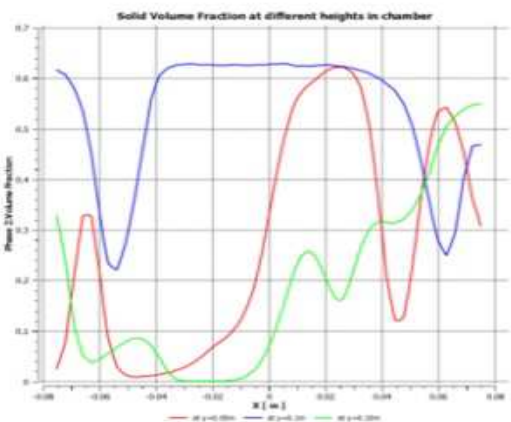

(d) $0.7 \mathrm{~m} / \mathrm{s}$

Figure 7: Sand Particle Concentration against the Radial Position for Different Bed Heights at Different Air Inlet Velocities

Figure. 8 represents the plot of radial variation of axial velocity of sand particles in chamber at different bed heights for different air inlet velocities. Sand particle velocities near wall are decreases and this may lead to the back accumulation of particles.

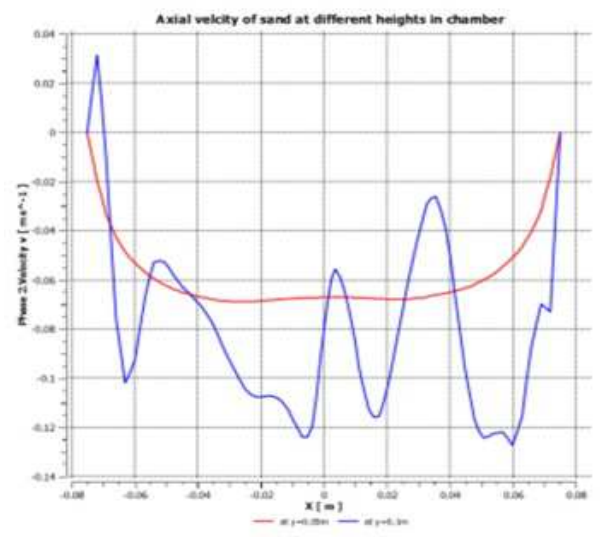

(a) $0.05 \mathrm{~m} / \mathrm{s}$

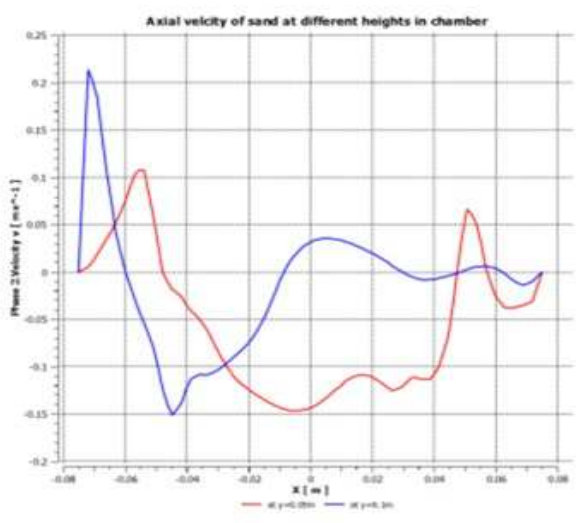

(b) $0.2 \mathrm{~m} / \mathrm{s}$ 


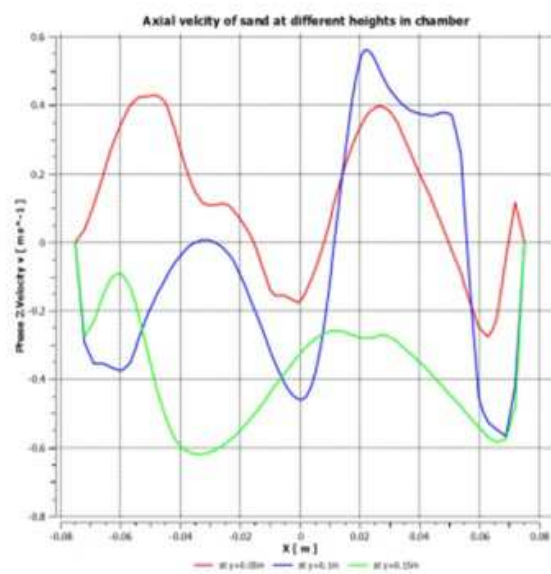

(c) $0.5 \mathrm{~m} / \mathrm{s}$

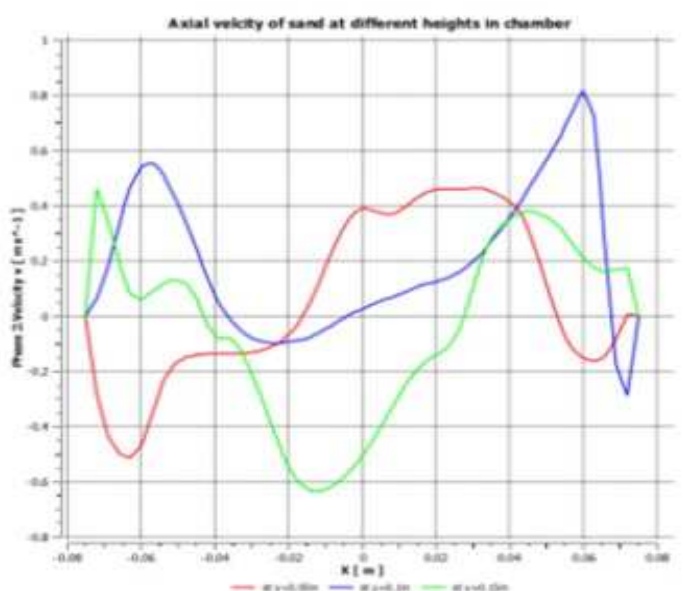

(d) $0.7 \mathrm{~m} / \mathrm{s}$

Figure 8: Sand Particle Velocity Distribution along the Radial Direction at Different Velocities for Different Axial Heights of $0.05 \mathrm{~m}, 0.1 \mathrm{~m}, 0.15 \mathrm{~m}$ and $0.2 \mathrm{~m}$

\section{CONCLUSIONS}

CFD simulations using ANSYS-Fluent software are carried out to investigate hydrodynamic behavior of bubbling fluidized bed. The bubbling flow regime is appeared above the air inlet velocity of $0.2 \mathrm{~m} / \mathrm{s}$. Bubbling character is increased with increase in inlet air velocities indicated by asymmetrical fluctuations of volume fractions in radial directions at different bed heights.

\section{REFERENCES}

1. Gidaspow. D, Multiphase Flow and Fluidization, First ed, London.1994.

2. Kunii. D, Levenspiel. O, Fluidization Engineering, Second ed., Butterworth-Heinemann, Boston. 1991

3. Ranade. V.V, Computational Flow Modeling for Chemical Chamber Engineering, Firsted. Academic press, New York.2002.

4. Huilin. L, Wentie. L, Feng, L, Guangbo, Z, Huilin, H.L., Wentie, L., Feng, L., Guangbo, Z., Yurong, H., Eulerian simulations of bubble behavior in a two dimensional gas-solid bubbling fluidized bed, Int. J. of Energy Research, 26, pp.12851293.(2002)

5. Grace. J.R, Taghipour .F, Verification and validation of CFD models and dynamic similarity for fluidized beds. Powder Technology pp.139, 99-110.2004

6. Bird. R.B., Stewart. W.E., Lightfoot, E.N., Transport Phenomena, Wiley.2002.

7. Shivam Bahuguna, Simulation of Particle \& Liqiud Impact on Water Film Under Equidense Conditions using Smoothed Particle Hydrodynamics (SPH), International Journal of Mechanical and Production Engineering Research and Development (IJMPERD), Volume 5, Issue 6, November - December 2015, pp. 1- 8

8. Taghipour. F, Ellis. N, Wong. C, Experimental and computational study of gas-solid fluidized bed hydrodynamics, Chemical Engineering Science, 60, pp. 6857-6867.(2005)

9. Kaneko. Y, Shiojima. T, Horio. M, DEM simulation of fluidized beds for gas-phase Olefin polymerization, Chemical Engineering Science, 54, pp. 5809-5821.1999.

10. Huilin. L., Yurong. H., Gidaspow. D. Hydrodynamic modeling of binary mixture in a Gas bubbling fluidized bed using the 
kinetic theory of granular flow, Chemical Engineering Science, pp. 1197-1205, 2003

11. Gobin. H. Neau, O. Simonin, J.Llinas, V. Reiling, J.L. Selo, Fluid dynamic numerical simulation of a gas phase polymerization chamber, International Journal for Numerical Methods in Fluids, 43, pp. 1199-1220. 2003

12. VanWachem. B. G. M., Schouterf. J. C. Krishnab. R., and Bleek .vanden. C. M., Eulerian Simulations of Bubbling Behaviour in Gas-Solid Fluidized Beds, Computers chem. Eng, Vol.22, pp. 299-306.1998

13. Zhong.W, Zhang. M, Jin. B. Maximum spoutable bed height of spout-fluid bed, Chemical Engineering, 124, pp. 55-62.2006

14. Lettieri. P., Saccone. G., Cammarata. L. Predicting the Transition from Bubbling to Slugging Fluidization Using Computational Fluid Dynamics ,Trans IChemE, Part A, Chemical Engineering Research and Design, 82(A8): 939-944., 2004

15. ChinmayeePatra, CFD SIMULATIONS OF FLUIDIZED BED BIOMASS GASIFICATION, A Thesis Submitted to the National Institute of Technology, Rourkela In Partial Fulfillment for the Requirements Of Master of Technology (Res.) Degree

16. BaharehEstejab, Francine Battaglia, Assessment of Drag Models for Geldart A particles in Bubbling Fluidized Beds, Journal of Fluids Engineering, 138(2015)

17. EmbarekBelhadj, Stephen Chilton Numerical simulation and experimental validation of the hydrodynamics in a $350 \mathrm{~kW}$ bubbling fluidized bed combustor, Int J Energy Environ Eng 7 (2016):27-35 